à saúde dos consumidores e à reciclabilidade e reutilização de produtos e embalagens. É um capítulo rico em exemplos de empresas que jâ tiveram fortes iniciativas "verdes".

A forma como essas iniciativas devem ser comunicadas ao público é o tema do capítulo 6 . Três aspectos básicos devem ser observados nessa comunicação: primeiro, a empresa deve criar o envolvimento do consumidor fazendono assumir um consumo responsável como algo positiyo para sua prốpria saúde e bem-estar; em seguida, deve despertar a credibilidade dos consumidores no desempenho do novo produto ou da nova embalagem e, finalmente, deve demonstrar seu interesse ambiental năo como um esforço isolado, mas como parte de uma política corporativa. Os certificados ambientais independentes, como os selos verdes, por exemplo, săo um meio eficaz que as empresas dispôem para comunicar o respeito de seus produtos e embalagens ao meio ambiente.

Através da exposição dos casos de duas empresas, no sétimo capítulo, Ottman mostra que estratégias ambientais não só podem formar a base de um negócio duradouro como também fornecer alavancagem frente aos concorrentes. A autora conclui: "O consumerismo ambiental oferece excelentes oportunidades de comunicaço, desenvolvimento de produto e habilidade de formar coalizoses construtizas com uma ampla gama de formadores de opinito corporativos e ambientais. Adotados em conjunto, essas estratégias reforçam-se umas às outras, de forma a modelar uma resposta complefa e crível aos interesses ambientais dos consumidores."

Fechando o livro, a autora aborda ainda algumas perspectivás futuras quanto a transportes alternativos, eficiência energética, controle de lixo sólido, proteção contra problemas ambientais, conservação de água e outros recursos naturais.

Para caracterizar, ainda mais, esse livro como uma contribuiçăo prática para os executivos de marketing, Jaquelyn Ottman propôe, em cada capítulo, a partír do capítulo 4 , algumas idéias para ação e apresenta nomes e endereços de inúmeras organizações ambientalistas, nos Estados Unidos e no Brasil, para os contatos que se façam necessários.

\section{JAPAN'S CAPITALISM: CREATIVE DEFEAT AND BEYOND}

\section{de SHIGETO TSURU \\ Cambridge: University Press, 1993.}

\section{por Gilmar Masiero, Doutorando em Administração na EAESP/FGV.}

ondições econômicas do Japão, política ecorômica, história do capitalismo japonês, relações econômicas internacionais, Estados Unidos e Japẫo säo as palavras-chave da oportuna contribuição de Shigeto Tsuru para um maior conhecimento da sociedade japone- sa. Aspectos institucionais até então negligenciados pela maioria dos estudiosos do Japão são brilhantemente trabalhados neste livro.

Obrilhantismo de Tsuru pode ser facilmente percebido em seus livros $e$ artigos ou mesmo em comentários de seus amigos. John Kenneth Galbraith, que prefacia o $\mathbf{l t}_{-}$ vro, afirma ao final deste que "após este livto, rintguém interessado no desenvolvimento econômico japo-

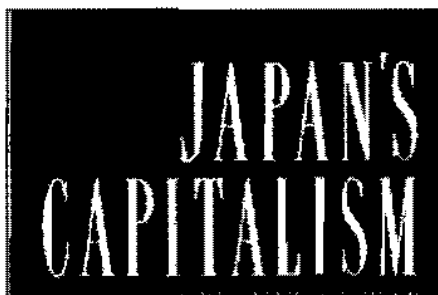
nês, suas perspectivas eo necessirio curso das poltiticas pode reclamat de algum problemo no acesso a cena econômica japonesa. Eninguêm que näo tentha lito este livro pode presumir completo conhecimento daquele desenvolvimento e daquela perspectiva. Existem palaoras fortes. Existe um significado maior".

Aos menos familiarizados com Tsuru recomenda-se a leitura das quatro páginas escritas por Mark Perlman a tîtulo de notas do editor. Através delas, o leitor fica sabendo, entre outras coisas, que o extensivo e näo ortodoxo trabalho do professor Shigeto em macroeconomia é largamente reconhecido e estimado no Oriente e no Ocidente. Esse reconhecimento se deve ao fato de o autor ter exercido várias funçôes importantes e recebido vários prêmios. Tsuru foi presidente da Associaçâo Internacional de Economia entre 1977 e 1980, ê membro da Academia Japão e, entre tantos outros, recebeu título honorário em Harvard (evento relativamente raro, em se tratando de cidadäos japoneses).

Tsuru nasceu em 1912 e hoje é professor emérito da Universidade de Hitotsubashi, onde lecionou Economia de 1948 ate 1972 e foi presidente de 1975 a 1985 . Em 1947 e 1948 , paralelamente à sua carreira acadêmica, foi vice-ministro do Conselho de Estabilizaçâo Econômica do Governo Japonês. Durante a presidência da Hitotsubashi, atuou também no Conselho Editorial do Asahi Shimbun (um dos mais importantes jomais do Japão). Além da docência no Japăo, lecionou em Harvard, Yale, John Hopkins, Rochester e Escola Delhi de Fconomia.

Mais de 80 anos de vida nos melos governamentais e acadêmicos japoneses e mundiais foram sintetizados em. 277 páginas organizadas em oito capítulos. Sem desconsiderar a histôria anterior a 1945 - fato relativamente raro na literatura econômica sobre o Japão - , Tsuru revisa o desenvolvimento japonês do imediato pós-guerra até nossos dias, considerando sempre a inserção do Japão no cenário internacional. Nesse cenário, todas as transformações econômicas do pôs-guerra e o recente término da guerra fria não foram suficientes para acabar ou fazer com que o 
tratado de segurança entre Estados Unidos e Japão perdesse sua razão de ser.

Esse tratado, que permeia toda a vida política e econômica japonesa do pós-guerra, é comentado nos primeiros capítulos do livro de Tsuru. A importância deste e de outros tratados, bem como a excelente seleção de temas de política monetária e fiscal ou de microeconomia, podem ser encontradas nos capítulos 1 a 8 . O capítulo 1, "A derrota e as reformas das Forças de Ocupação", é desenvolvido através dos subitens: "Consequiências da derrota na guerra", "A política americana inicial de ocupação", "As idéias iniciais de reforma do lado japonês", "As reformas das Forças de Ocupação".

O capitulo 2, "O caminho da recuperação", contém "A mudança da política americana sobre o Japão", "Detendo as tendências inflacionárias", "Estabelecendo uma taxa de câmbio única", "A Guerra da Coréia e as conseqüências", "O tratado de paz". "O período de altas taxas de crescimento" é tratado no capítulo 3, através de "O 'milagre' do rápido crescimento", "Capitalismo rejuvenescido", "De onde vem a demanda efetiva" e "Transformação da estrutura industrial".

"O papel do governo no período de elevado crescimento" é discutido no capítulo 4, que é desenvolvido através dos subitens "Planejamento geral pelo governo", “Controle administrativo", "Reclamações para localização de fábricas", "Medidas especiais de alívio tributário para indústrias", "A política de baixas taxas de juros", "Liberalização do comércio e da entrada de capitais", "Subsídios sobre a água e eletricidade". O capítulo 5, "O ponto de virada do cometa", discute "O primeiro choque do petróleo em 1973", "A rastejante inflação estrutural", "Preocupações ambientais levantadas" e "Reflexões sobre o conteúdo de bemestar do índice PNB".

Os elevados preços no Japão são discutidos no capítulo 6, "A dupla revolução de preços", através de sete subitens: "A coincidência de duas revoluçōes de preços", "O caso clássico de revolução de preços", "As conseqüências da revolução de preços do choque do petróleo", "Revolução de preços dos lotes urbanos", "Principais causas da revolução de preços da terra", "As conseqüências socioeconômicas da revolução dos preços da terra e as contramedidas" e "Má administração macroeconômica".

Os capítulos 7 e 8, "A marcha do corporate capitalismo" e "Para onde vai o Japão?", tratam do "Capitalismo triunfante?", "Um novo estágio do corporate capitalismo no Japão", "A tendência de globalização", "Privatização", "A tendência convergente dos dois sistemas", "A economia mista como um modo de produção" e "As perspectivas da economia japonesa e o papel do Japão no mundo".

O corporate capitalismo discutido por Tsuru no capítulo 7 é do tipo predominante no Japão, um capitalismo onde se privilegia a criação de conglomerados e a globalização. Dessa maneira, são renovados o interesse e a importância do controle da propriedade" "freqüentemente relacionada a redes de sociedades anônimas mutuamente associadas". No préguerra, o controle da propriedade era familiar, através dos zaibatsu. No pós-guerra, embora Tsuru não mencione o termo, esse controle é efetuado através dos keiretsu.

Pela seriedade com que as temáticas foram tratadas, a leitura do livro de Shigeto Tsuro não só é recomendável como também é obrigatória a todos os estudiosos da área econômica envolvidos com estudos sobre o Japão ou não. Considerando os desacertos de nossas políticas de estabilização e desenvolvimento, o estudo da experiência japonesa é indispensável a tódos os nossos ministros da Economia e suas equipes. Professores e alunos de pós-graduação em Economia, Ciência Política, Administração e Sociologia também devem aprender com a experiência japonesa sistematizada em Japan's capitalism.

\section{LA LOGIQUE DE L'HONNEUR - GESTION DES ENTREPRISES ET TRADITIONS NATIONALES}

\section{de PHILIPPE D'IRIBARNE}

Paris: Editions du Seuil, 1989, 279 p.

por Fernando C. Prestes Motta, Professor Titular do Departamento de Administração Geral e Recursos Humanos da EAESP/FGV.

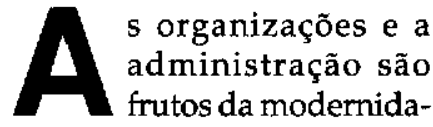
de, e esta é responsável por um grande sonho. A modernidade pretendeu libertar a vida dos homens, as relações que eles mantêm com seus semelhantes, as formas pelas quais eles se governam e representam o mundo, de toda a crença, de todo o preconceito, de todo o respeito às tradições, de todo o envolvimento visceral com um solo, um povo, uma linhagem. Para a modernidade, nada existe além da natureza e da

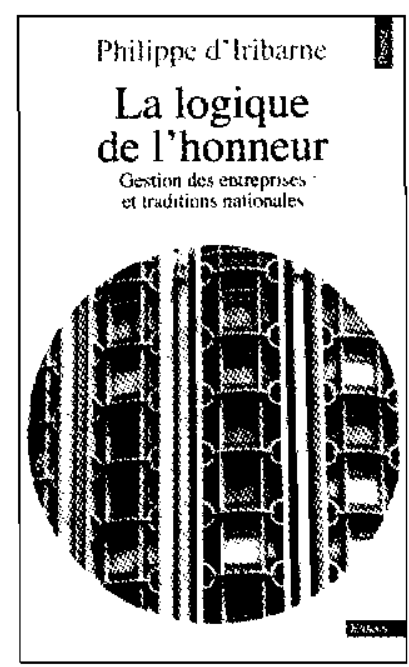

